\title{
AS CIÊNCIAS HUMANAS E O RACIONALISMO CIENTÍFICO
}

Roberto Gomes*

SÍNTESE - Este artigo busca mostrar o vínculo existente entre os acontecimentos que deram origem ao aparecimento do Racionalismo Científico e da natureza do Homem que será objeto de análise por parte das Ciências Humanas. O abandono de Deus - no dizer de Laplace, uma "hipótese" da qual prescinde - é acompanhado de uma radical transformação na imagem da Natureza e gera um projeto de criação e modelagem de um Homem acessivel ao Saber extraído das Ciências Empíricas. Neste projeto, Saber, Fazer e Poder mantêm um vínculo que determinará a natureza do Homem e das Ciências Humanas.

ABSTRACT - This article aims to show the existing link between the events which gave origin to the appearance of Scientific Rationalism and the concept of nature of Man, which will be the object of analysis by the Humanities. The rejection of God - in the words of Laplace, a "hypothesis" he dismisses - is accompanied by a radical transformation in the image of Nature and generates a project of creation and modelling of a Man accessible to Knowledge extracted from the Empirical Sciences. In this project, Knowledge, Making and Power maintain a link which will determine the nature of Man and of the Humanities.

\section{$1-1632$}

Pensar a gênese das Ciências Humanas - e, de modo especial, o aparecimento do Homem de que elas falam - exige a retomada do percurso que, no Ocidente, resultou na criação da Ciência Moderna. Isso permitiria uma dupla investigação. De um lado, vincular a pretensão de cientificidade presente naqueles saberes à história do conhecimento em geral, reconstruindo-se as linhas gerais do projeto de saber que Durkheim chamou de "racionalismo científico". ${ }^{1}$ De outro, compreender a natureza deste Homem que passa a ser objeto de um olhar científico. Estas duas questões estão ligadas a dois acontecimentos decisivos: a morte de Deus e o nascimento/eclipse do Homem.

O modelo de cientificidade que triunfou no Ocidente surgiu no século XVII. É certo que poderiamos descobrir traços de preocupação científica (ou científica) antes desta data (e as datas sempre são problemáticas), mas restaria saber se tais atitudes precursoras estariam presentes nos discursos analisados ou em nosso ângulo de avaliação. Afinal, a leitura que fizermos estará, neste caso, comprometida. Talvez possa-

Escritor e professor de Filosofia da Universidade Federal do Paraná.

1 DURKHEIM, Émile. Regras do método sociológico. Trad. Margarida Garrido Esteves. Col. Os Pensadores, v. XXXIII. São Paulo : Abril Cultural, 1973. A respeito do racionalismo científico em Durkheim, ver meu artigo "O saber sem desejo" (Durkheim e as Ciências Humanas), publicado na revista Veritas, dez. 94.

\begin{tabular}{l|l|l|l|l|l|} 
VERTTAS & Porto Alegre & v. 40 & $\mathrm{n}^{2} 157$ & Março 1995 & p. 79-86
\end{tabular}


mos admitir que, apesar de vestígios de uma atitude experimental - podemos lembrar que Galeno, no longínquo segundo século d.C., adotava procedimentos que indicam uma postura de observação empírica - até o século XVI tudo se move a partir do infindável paralelismo, via simpatias e antipatias, entre o macrocosmo e o microcosmo, na busca do sentido que seria dado pela presença das marcas de Deus impressas no mundo. Só no século XVII surgem estas novas criaturas que o próprio homem forja a partir do momento em que prescinde das intenções divinas: a Ciência e a Razão.

Ao ver de Edwin A. Burtt a "visão moderna do mundo", que tem apenas três séculos de idade, se define sobretudo pelo chamado problema do conhecimento. ${ }^{2}$ Este lugar central concedido à epistemologia decorre de uma nova concepção do Mundo e do Homem, já que, na Idade Média, "o conhecimento não era um problema para a Filosofia". Este contraste entre o pensamento medieval e moderno se torna claro ao levarmos em conta que o Homem é, para o pensador medieval, o centro do universo. Diz Burtt: "todo o mundo da natureza estava teleologicamente subordinado a ele e seu destino eterno". ${ }^{3}$

Na verdade, embora o Homem ocupe um lugar central ao longo da Idade Média, é preciso notar que ele aí se encontra por ser uma criatura de Deus. Criado num mundo que deve lhe servir de morada, tem com este uma afinidade intrínseca: ser privilegiado, cabe a ele ler os sinais que Deus disseminou ao longo de sua criação. É Deus, portanto, o centro. Seja como for, tem razão Burtt ao dizer que esta visão torna o mundo "totalmente inteligivel" para a mente humana, não havendo lugar para a questão do conhecimento.

Razão pela qual, mesmo em pensadores que tendemos a ver como anunciadores dos tempos modernos, Deus se impõe como principio explicativo do mundo, o que será interditado a um espírito rigorosamente moderno. As construções astronômicas de Copérnico e Kepler estão repletas de exemplos desta postura. Mesmo em Descartes, Deus é a garantia última de que não somos vítimas de uma farsa cósmica.

Ainda que se insinue e divulgue gradualmente na mente dos homens - afinal, como suportar, de um só golpe, tamanha transformação? - o salto entre estes dois mundos é tão contundente que alguns historiadores, como Robert Lenoble, ${ }^{4}$ chegam a fixar uma data para tal rebuliço epistemológico: 1632. É neste ano que Galileu publica os Diálogos sobre os dois principais sistemas do mundo.

Questão controversa, não é imediatamente óbvio que os méritos de Galileu cheguem a tanto. Talvez haja um certo exagero na valorização da figura histórica de Galileu, o que explica o rol de restrições com que o cerca um polemista como Arthur Koestler, lamentando que "a fama deste notável gênio repouse sobretudo em descobrimentos que nunca fez e em feitos que nunca realizou [...] Galileu não inventou o telescópio, nem o microscópio, nem o relógio de pêndulo. Não descobriu a lei da inércia, nem o paralelogramo das forças e dos movimentos, nem tampouco as manchas solares. Não contribuiu para a astronomia teórica, não atirou pesos da torre inclinada e não provou a verdade do sistema copernicano. Não foi torturado pela Inquisição, não padeceu nas masmorras, não disse eppur si muove e não foi um mártir da ciência." ${ }^{5}$

2 BURTT, Edwin A. As bases metafísicas da Ciência Moderna. Trad. de José Viegas Filho e Orlando Araújo Henriques. Brasilia : Editora da UnB, 1991. 268p. p. 9.

3 Idem, p. 11.

4 LENOBLE, Robert. A História da Idéja de Natureza. Trad. Teresa Louro Pérez. Lisboa : Edições 70, 1990.

5 KOESTLER, Arthur. O Homem e o Universo. Como a concepção do Universo se modificou através dos tempos. Trad. Alberto Denis. São Paulo : Ibrex, $2^{2}$ ed., 1983. p.244. 
No entanto, Galileu teria apenas fundado a ciência da Dinâmica - a parte da Física que estuda o movimento dos corpos, relacionando-os às forças que os produzem - 0 que por si só faz dele um dos construtores da nova imagem do mundo, pois "forneceu o indispensável complemento às leis de Kepler para o Universo de Newton". ${ }^{6}$ Com isso pode ser incluído entre os gigantes sobre cujos ombros Newton admite ter se apoiado (os outros dois são Descartes e Kepler).

Assim, é Galileu que irá desempenhar o ponto de não-retorno na história do conhecimento humano.

\section{2- Os labregos}

Para que tal mutação ocorresse, no entanto, seria preciso superar o abismo existente, desde os Gregos, entre Ciência e Arte. Cabe registrar que este abismo ainda está presente no Renascimento. O desprezo aristocrático que os Gregos (Platão e Aristóteles entre eles, é claro) manifestam pela técnica - techné - (contingente e incerta) em oposição à ciência - épistème - (saber essencial e seguro), será contestado por esta revolução de engenheiros, no dizer de Robert Lenoble. Se o sábio grego é um homem livre, "o artesão é, na Antigüidade, um escravo, na Idade Média, um labrego"? Mesmo Descartes se ressentia pelo fato de que, a partir da Matemática, se houvesse edificado apenas algo de uma nobreza tão discutivel quanto as "artes mecânicas".

Em 1632, portanto, se a esta data pode ser atribuída tamanha importância, "o engenheiro conquista a dignidade de sábio". ${ }^{8} \mathrm{O}$ conhecimento já não será contemplação - no que se fartou durante séculos - mas representará uma arma de intervenção do Homem sobre a Natureza.

Esta reviravolta na valorização dos engenheiros, altera a concepção de Mundo e impõe o triunfo da matematização e da geometrização, como assinala Alexandre Koyré. Passa a predominar a linguagem matemática e a abordagem geométrica, o que representa o triunfo da mente cartesiana. Além disso, se instala um anti-teologismo: Deus é expulso do mundo. À imagem anterior do Universo, na qual a presença de Deus é central e monopolizadora, segue-se a representação de um Mundo que será progressivamente abandonado a si mesmo: o seu sentido já não será justificado através de um ser transcendente. É esta a hipótese da qual Laplace abre mão. Assim, as questões da Filosofia e do Conhecimento deixarão de girar em torno da trindade Deus/Mundo/Homem - aquele que determina e sustenta o sentido, aquilo no que o sentido está inscrito e aquele que lê o Livro do Mundo - para girar em torno da dualidade Homem/Mundo, o que, no dizer de Galileu, constituirá o Livro da Natureza, fundado na dualidade Sujeito/Objeto.

Desta forma, se o engenheiro é um sábio, "conhecer é fabricar" ${ }^{19}$ e torna-se uma questão nobre a investigação de como o Mundo funciona, o que equivale a procura de como o Mundo foi concebido pela divindade, pois Deus, embora eclipsado epistemologicamente, é ainda uma entidade presente através da fé. Ocorre, pois, um triplo acontecimento: o eclipse de Deus, o aparecimento do Homem como criatura condenada a fundar seu próprio conhecimento, e um Mundo que se torna um problema, pois a afinidade intrínseca entre ele e o Homem, que era dada por Deus, está perdida.

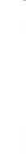

Idem, p. 244.

7 LENOBLE, Robert. Op. cit., p. 259.

8 Idem, p. 260.

9 Idem, p. 260. 
Acontecimentos que são atravessados por uma viga mestra: a ação sobre o Mundo será a partir de agora a maneira privilegiada de se superar a "questão do conhecimento". Aí se buscará a unidade perdida.

\section{3 - A solidão cósmica}

Desta forma, para se instalar o racionalismo científico, foi necessário que a Natureza perdesse sua finalidade. Deus deixa de ser um princípio explicativo e se nega ao cientista o recurso ao argumento fundado na divindade. A partir deste momento, a explicação de Copérnico para a posição central do Sol no Universo deixa de ser legítima.

Se diz que Copérnico, em 1513, reuniu oitocentas pedras e uma barrica de cal para construir uma torre que lhe serviria de observatório. Nas investigações que realiza dos corpos celestes, torna-se evidente que são necessárias correções nas teorias de Ptolomeu, em particular nas teorias geométricas do movimento planetário: estes se movem em circulos, mas não com velocidade uniforme. Assinalado este defeito, Copérnico passa a refletir se não haveria uma disposição mais sensata de círculos, "na qual tudo se moveria uniformemente em torno de seu próprio centro, como requer a regra do movimento absoluto".

É curioso que a opção heliocêntrica acabe se impondo não por uma notória incapacidade da teoria geocêntrica, nem porque esta não fosse capaz de explicar os fatos observados. Antes que Tycho Brahe observasse o aparecimento de uma Nova e que manchas solares fossem detectadas, já havia uma recusa e um mal-estar com relação ao geocentrismo. Ele cai no descrédito não tanto por questões teóricas ou por problemas epistemológicos insolúveis - o complicado sistema de círculos de Ptolomeu feria antes a exigência de rigor e simplicidade racional do que as possibilidades de explicação dos fenômenos observados - quanto por se chocar com a nova experiência do Mundo que vai se impondo.

O espaço em que desde sempre se vivera começa a parecer exíguo ao homem do século XVI. Os limites do mar e da terra precisam ser superados nas mentes dos teóricos já que foram superados pelos navegadores. Noutra dimensão, os mundos talvez sejam inúmeros e infinitos, o que determina um reposicionamento radical com relação ao espirito grego: a imobilidade, a limitação, o finito, que haviam se imposto ao Mundo cristão, passam a ser ultrapassados por uma aceitação do mutável, do ilimitado, do infinito. Galileu se dedica a pensar o movimento. Giordano Bruno, os infinitos mundos. O geocentrismo não é abandonado por razões meramente teóricas, mas porque já não expressava os desejos do Homem deste século.

É no limite inicial desta transformação que Copérnico percebe que se colocasse, como já o haviam feito alguns gregos, o Sol no centro do Universo e a Terra como um simples planeta, teria um modelo mais adequado para explicar o que podia ver nos céus. Tal adequação tinha por meta a maior simplicidade e conseqüente redução do número de epiciclos e não apenas a refutação a partir de observações feitas - Copérnico, como se sabe, fez poucas observações e errou em muitas delas. As razões para esta mudança eram sobretudo científicas, no sentido de que decorriam de seus cálculos e observações astronômicas, mas nelas não deixava de estar presente, de uma forma decisiva, o hermetismo. Na mesma página de Das revoluções dos corpos celestes na qual aparece a idéia do heliocentrismo, ele escreve: 
"Imóvel, no entanto, no meio de tudo está o Sol. Pois nesse mais lindo templo, quem poria esse candeeiro em outro ou melhor lugar do.que esse, do qual ele pode iluminar tudo ao mesmo tempo?"

Copérnico valoriza, simultaneamente, a observação e as concepções teleológicas - mas o fundamento da explicação é Deus. Este híbrido impede que ele possa ser um pensador rigorosamente moderno e o vincula a uma longa tradição. A partir do acontecimento da ciência moderna, o argumento de Copérnico perde inteiramente sua validade. Num movimento brusco, o fundamento estava deslocado: já não era possivel enunciar esta proposição.

Decorrência: com o sumiço de Deus, sumirão os sinais que orientavam o Homem na leitura do cosmo até a Renascença. É diante desta solitária máquina do mundo que Galileu irá dizer: "o livro da Natureza está escrito em linguagem matemática". Estava estabelecida, então, a base de toda Física. "Ao reduzir a Matemática à extensão, Descartes obtém essa segurança de crer que a Física é a Geometria aplicada". ${ }^{10}$

Se até este momento o Mundo foi pródigo em sinais e avisos, daqui para diante a Natureza será concebida como uma máquina, cega e obstinada, e a Ciência e a Técnica se dedicarão a seu conhecimento e domesticação. De tal forma isso se generaliza e com tamanha rapidez, que quase de um momento para outro se impõe como critério para toda concepção de Ciência que pretenda ter validade a partir do século XVII. Um novo princípio de exclusão/inclusão havia se instalado na épistème ocidental.

\section{4 - Um novo espaço: o sujeito}

Parte determinante desta trajetória, o Sujeito cartesiano, será no entanto igualmente eclipsado pelo mundo do Objeto, agora pensado mecânica e geometricamente, através de linguagem matemática. Nesta eclipse do Sujeito se fundará o espírito científico.

No entanto, nada é gratuito. Há um preço a pagar. É preciso ter presente que a este acontecimento na ordem do saber corresponde um abandono do Homem. Ele passa a existir, mas, desligado da tutela divina, se perceberá cada vez mais só e desesperado. Se o triunfo da Razão lhe oferece um sentimento de poderio, produz igualmente uma experiência de profundo abandono. Embora a crise espiritual acarretada por esta solidão só vá se manifestar plenamente nas reflexões de Pascal, o germe corrosivo estava lançado. O Homem se vê radicalmente só. Mersenne registra: "Não vos parece", escreve ele a Ruarus, "um anúncio de fim do Mundo?"11

Assim, deste desastre anunciado, emerge uma nova figura na História: o Homem. Só, sábio, engenheiro, criador, ele é o senhor da Natureza a partir de agora. Através da Técnica e da Ciência, poderá exercer, à maneira dos engenheiros, o que imagina sua verdadeira essência - o Pensamento - e sua soberania - o conhecimento e o domínio do Mundo. Apesar disso, não sente ainda um conflito irreconciliável entre esta exaltação da Razão e da Ciência e a fé em Deus. Ao ver do homem do século XVII, neste momento, "edificar uma ciência verdadeira é [...] trabalhar para a causa de Deus." ${ }^{12}$ Mersenne imagina uma santificação através da Física e, nesta imitação de Deus, o Homem se faz digno do criador. "O físico da Idade Média eleva-se a Deus

10 LENOBLE, Robert, op. cit., p. 261.

11 In: LENOBLE, Robert, Op. cit., p. 263.

12

LENOBLE, Robert. Op.cit., p. 267. 
descobrindo suas intenções, as finalidades da Natureza, o físico mecanicista eleva-se a Deus penetrando o próprio segredo do Engenheiro divino, colocando-se no seu lugar para compreender como ele a forma, como o mundo foi criado..13

Emerge, pois, por detrás do desastre da imagem renascentista do mundo, a figura do Homem. E uma nova problemática, religiosa e moral, se instala. No século XVII, apesar das aparências em contrário, Religião e Ciência caminham lado a lado. A Ciência é uma aliada da Teologia, serve à Religião, não contradiz os atos do criador, embora seja ilegítimo explicar o Mundo a partir de Deus. É este Deus que Pascal lamenta ter sido reduzido ao "piparote" inicial. Daí para a frente, tudo fica a cargo do Homem.

O Mundo-máquina, concebido à semelhança do mecanismo de um relógio, despido de valores, irá aos poucos ser aliviado de sua pesada divindade. $\mathrm{E}$ isso se dará numa velocidade crescente. Tycho Brahe, em 1573, anuncia o nascimento de uma nova estrela e, em 1577, faz a observação de um cometa, experiência que repetiria várias vezes nos anos seguintes. Galileu, em 1610, focaliza os satélites de Júpiter pela primeira vez, descobre montes e crateras na Lua e manchas no Sol. O Mundo incorruptível das esferas fixas estava condenado. Era o fim dos céus imutáveis. E, ao contrário dos Gregos, que viam na limitação, na finitude, um sinal de perfeição, o Mundo agora será infinito, o que acarreta um pavor indizivel para homens abandonados a si mesmos. É Pascal quem expressa este abandono cósmico: "o silêncio destes espaços infinitos me aterroriza".

Abandonado o recurso a Deus e instalado o Homem como ser pensante, as conseqüências, no entanto, não deixam de se desenvolver. Os animais e plantas, à semelhança do resto do Universo, passam a ser vistos como máquinas e o mecanicismo será impiedoso com o vitalismo renascentista. O Cosmo não será mais perscrutado em função de simpatias e antipatias, de analogias e sinais e os paralelos entre o micro e macro são abandonados. Tudo se reduz ao geometrismo apontado por Koyré - estamos diante de um mundo espacializado.

Se o Homem já não pode encontrar Deus na Natureza, o mecanicismo nela apontado ameaça invadi-lo. O refúgio será seu coração (Pascal), ou seu pensamento (Descartes). Cria-se, assim, um novo espaço: o da subjetividade psicológica e da intencionalidade moral. O Homem mergulha em si mesmo em busca de Deus e do sentido. Mas, desgraçadamente, irá encontrar angústia, solidão e o rigorismo kantiano. Irá se descobrir como sujeito, mas logo saberá estar sujeito a leis mais fortes, como as da Biologia, da Sociedade, do Inconsciente, da Natureza.

Com o triunfo do mecanicismo, a morte epistemológica de Deus fará com que o Homem se descubra vazio e só. Mas, ao lado deste desespero, e sendo talvez a sua outra face, se instaura um ufanismo de caráter messiânico que busca preencher este vazio e abrandar esta solidão através da embriaguez provocada pela dedicação à causa do progresso que seria proporcionado pela ciência. Entre outras promessas, a Razão permitiria ao Homem viver cientificamente.

\section{5 - Eis o Homem}

Síntese entre Conhecimento e Arte, a Ciência Moderna será simultaneamente saber e fazer. Trata-se de desvendar leis (saber) para melhor dominar (fazer). Assim, a

13 Idem, p. 260. 
"revolução dos engenheiros", ao se estender ao Homem, irá lhe impor a mesma regra: é preciso conhecer para administrar seu comportamento.

Entidade vazia, que perdeu sua ligação essencial com Deus, o Homem é agora uma criatura aberta, tabula rasa pronta a cumprir os desígnios que o racionalismo científico lhe impuser. O homem molda o Homem. Estamos longe, porém, dos exercicios de autoconhecimento orientais, ou de uma iluminação existencial ou mística, e também não se trata do "conhece-te a ti mesmo" socrático. Aqui o Conhecimento se volta para o exercício de um poder equivalente ao que é exercido sobre a Natureza. No entanto, se com relação à Natureza o que orienta o cientista são as leis "objetivas", com relação ao Homem tais leis se encontram não apenas na Natureza, mas na sociedade que ele mesmo moldou. O fazer a si mesmo, portanto, implica moldar um Homem à imagem da ordem social nascente: o capitalismo. Há, pois, um laço não determinístico, mas inevitável, entre o racionalismo científico e a nova ordem econômica.

Não é sem razão, portanto, que a Psicologia iniciará valorizando a sensação, as reações, os estímulos, as respostas, o controle do que se passa a chamar comportamento (em oposição às noções agora arcaicas de alma ou psique) - sempre numa perspectiva do melhor ajustamento e do melhor desempenho, razão pela qual as análises quantitativas terão enorme fortuna. Esta é a imagem do Homem-máquina destinado a operar no interior da sociedade capitalista. Se é preciso mão-de-obra, desempenho, obediência a horários e não aos ritmos da Natureza, é preciso que seja imposta ao homem uma disciplina férrea. A Psicologia, diligente, providenciará os instrumentos para que isso seja factivel.

Da mesma forma, o projeto durkheimiano envolve a reafirmação da ordem social, das regras e leis presentes no corpo social, bem como uma submissão à "objetividade" da ordem social. O Homem à imagem do racionalismo científico é aquele que se funde com a lógica da produção, da hierarquia, da obediência - e afasta de si o demônio da revolta, do louco, do irracional, justamente o que assombrou a Europa desde a Revolução Francesa.

A gênese das Ciências Humanas, portanto, exige, de um lado, a morte de Deus e de seus desígnios, e, de outro, a extensão à totalidade do real do procedimento de saber/fazer que dá sentido ao conhecimento moderno. Mas exige igualmente que os instrumentos nascidos nas ciências empíricas (geometrização, linguagem matemática, experimentação, objetividade, isenção do observador, etc.) se fundam com os grandes temas universais (a loucura, a morte, o desejo, o medo, a sociedade, a história) da Filosofia e das religiōes, para deles fazer uma nova síntese num nível nunca atingido anteriormente: o poder soberano sobre o Homem.

Resta, porém, a questão: de que homem se trata? A originalidade de Foucault e a razão pela qual despertou tanta fúria e ranger de dentes entre psicólogos e sociólogos é que ele lhes roubou a "objetividade" que as Ciências Humanas acreditavam haver capturado para sempre. Quem é denunciado na obra de Foucault é o Homem criado à imagem e semelhança do racionalismo científico.

Certamente Foucault não corresponde ao "anti-humanista" e menos ainda ao pensador "desumano" que quiseram fazer dele. O que anuncia é claro: o homem que morre é o homem que acabou de nascer: nasce no século XVII e morre no século XX, junto com a ascensão e o declínio do racionalismo científico. Ao invés de um paralisante humanismo (ou, pior ainda, o rótulo absurdo e tolo de estruturalista) suas análises abrem a possibilidade de criação de um novo Homem ou, como dizia Guattari, de um novo "povo". 
Se a Razão representou a exclusão do louco, o encarceramento dos marginais, o eclipse do trágico, a submissão à "objetividade" social e natural, o anúncio de sua morte pode ser o primeiro passo na direção da libertação.

Fora do racionalismo científico, o Homem é um possível e importa menos saber o que é ou foi, mas o que está sendo a cada momento. O seu ser é o seu devir. Se as Ciências Humanas se mostrarem incapazes de pensar este devir, elas estarão igualmente condenadas ao desaparecimento, juntamente com o homem que criaram e perseguem: este homem que não é nenhum dos homens e menos ainda o seu devir, mas uma construção compativel com o racionalismo cientifico.

Se este homem morre, se abre a possibilidade de seu devir e este rio que Heráclito amava seguirá correndo e se transformando para sempre. 